\title{
Prescribing Patterns of Drugs in Outpatient Department of Paediatrics in Tertiary Care Hospital
}

\author{
Lita Susan Thomas*, Selvaraj Lavanya, Murugaiyan Sudaroli , George Praveen Kumar \\ Department of Pharmacy Practice, C.L.Baid Metha College of Pharmacy, Chennai.
}

\begin{abstract}
Paediatrics differs from adult medicine in many respects. Infants and children suffer from frequent but usually non serious illnesses. Effective medical treatment of paediatric patient is based upon an accurate diagnosis and optimum course of therapy, which usually involves a medication regimen. The aim of the study is to ascertain the disease pattern and drug prescribing pattern for outpatients attending the paediatrics services (OPD) in a tertiary care hospital. A total of 500 prescriptions were collected and analyzed. The average number of drugs per prescription was $3.74 \pm 1.02$. Upper respiratory tract infection was the most common reason for attending the paediatrics outpatient department [173 patients $(34.6 \%)$ ]. The other common diagnosis were Bronchitis [81 patients (16.2\%)], Acute gastroenteritis [28 patients (5.6\%)], Fever [22 patients (4.4\%)], Asthma [13 patients $(2.6 \%)$ ], Pneumonia [1 patient $(0.2 \%)$ ], others [75 patients $(15 \%)$ ] and Combination [107 patients $(21.4 \%)$ ]. Antibiotics were the most commonly prescribed category followed by NSAIDs. Appropriate drug utilization studies have been found to evaluate whether drugs are properly used and utilized in terms of medical, social and economic aspects.
\end{abstract}

Key words: Antibiotics, Department, Drug utilization Outpatients, Paediatrics, Prescription pattern.

\section{INTRODUCTION}

Prescribing pattern studies are powerful exploratory tools to ascertain the role of drugs in society. In a tertiary care centre, prescribing is expected to be judicious, appropriate, safe, effective and economical. The ultimate goal is to achieve rational and effective medical care, particularly in the economically developing countries. Considering these facts, this study is planned to analyze the prescribing pattern in pediatric patients at a tertiary care hospital. Paediatrics is the branch of medicine dealing with the development, diseases and disorders of children Drug therapy is considered to be major component of paediatric management in healthcare setting like hospital. Effective medical treatment of a paediatric patient is based upon an accurate diagnosis and optimum course of therapy, which usu- ally involves a medication regimen. ${ }^{2}$ Infants and children are especially vulnerable to contract illnesses and to the harmful effect of drugs due to differences in pharmacodynamics and pharmacokinetics. ${ }^{3}$ Compared to adult medicines, drug use in pediatrics is not extensively researched and the range of licensed drug in appropriate dosage form is limited. $^{4}$

Epidemiological evaluation of medicine use in elderly is now a highly visible topic, but drug prescribing studies in pediatric patients have been limited. The need for the safe and effective drugs for use in sick neonates, infants, children and adolescents requires the establishment of thoughtful drug therapy strategies. ${ }^{5}$ The study of prescribing patterns seeks to monitor, evaluate and if necessary suggest modifications in prescrib-
DOI: $10.5530 /$ ijopp.7.4.4

Address for correspondence: Dr. Lita Susan Thomas C. LBaid Metha College of Pharmacy,

Jyothi Nagar, Thorapakkam, Chennai-600097.

litasthomas@gmail.com

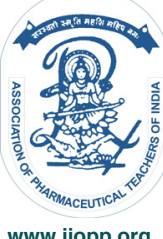


Table 1: Paediatric outpatient characteristics

\begin{tabular}{ll}
\hline PARAMETERS & Number of Patients (\%) \\
\hline \multicolumn{2}{c}{ Age } \\
\hline 0-4 weeks & $24(4.8 \%)$ \\
4 weeks-1yr & $187(37.4 \%)$ \\
$1-6$ years & $227(45.4)$ \\
$6-12$ years & $62(12.4)$ \\
\hline \multicolumn{2}{c}{ Sex } \\
\hline Male & $273(54.6)$ \\
Female & $227(45.4)$ \\
\hline
\end{tabular}

ing practices to make medical care rational and effective. $^{6}$ The assessment of drug utilization is important for clinical, educational and economical reasons and study focuses on effective medical treatment of pediatric patients with accurate diagnosis and selecting the proper drug regimens, avoiding unnecessary use of antibiotics and minimizes the prescription errors.

The use of antimicrobial agents, especially antibiotics has become a routine practice for the treatment of paediatric illnesses. However there are also reports of an irrational use of antibiotics which may even lead to infections that are worse than the originally diagnosed ones.

\section{MATERIALS AND METHODS}

An observational and prospective study was carried out for six months from June to December 2013. The study site was Paediatric Out Patient Departments (OPD) of The Voluntary Health Services, Chennai. The institutional ethical committee permission was taken to conduct this study. A total number of 500 prescriptions were selected on random basis to minimize bias. The information such as age, sex and body weight was recorded. The drug data such as name of the drug, dosage form, dosing frequency, duration, route of administration and diagnosis data were also noted. The data obtained \& the patient related parameters were computed using SPSS 16 version. The results were presented as percentage and mean \pm Standard deviation (SD).

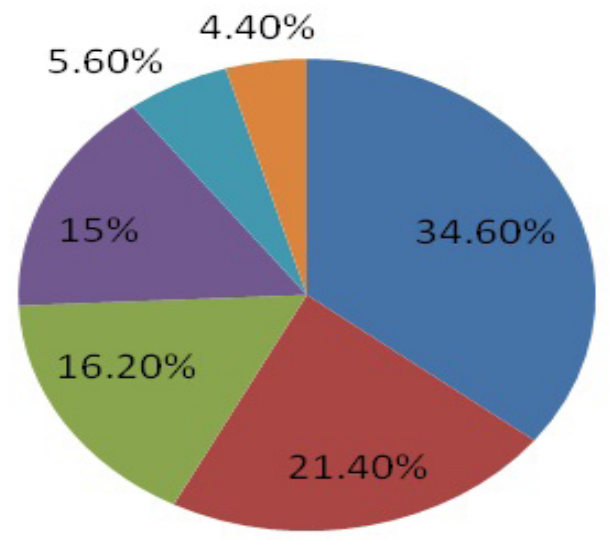

Figure 1: Profile of basis of morbidity

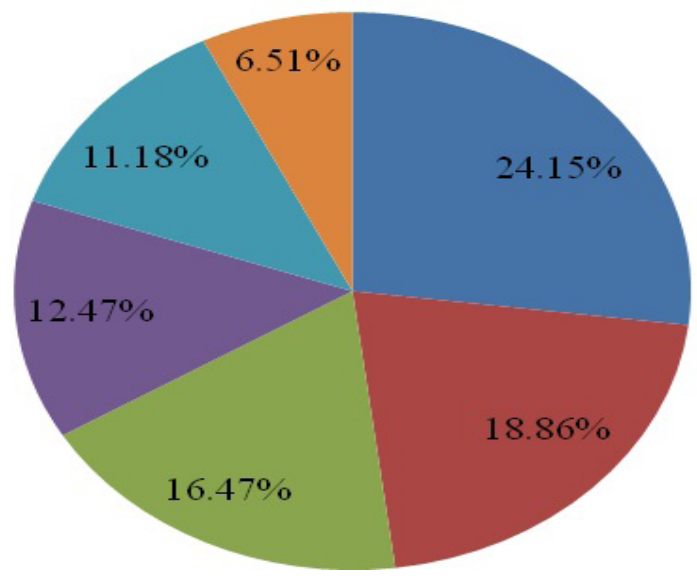

Figure 2: Classes of drugs prescribed

Upper respiratory
tract infection
Combination
Bronchitis
Others
Acute
gastroenteritis
Fever




\section{RESULTS}

A total of 500 prescriptions were analysed. The neonates were 24 (4.8\%). The male patients were $273(54.6 \%)$ and female patients were 227 (45.4\%). The distributions and proportions are as shown in Table 1.

Majority of the paediatric patients were suffering from upper respiratory tract infection (34.6\%) followed by bronchitis and acute gastroenteritis. The number of drugs per counter was found to be with a minimum of 0 and maximum of 5 drugs. The profiles of basis of morbidity are as shown in Figure 1

The average number of drugs per prescription was $3.74 \pm 1.02$. A total of 1627 drugs were prescribed and most frequently prescribed drug class was antibiotics (24.15\%) followed by nasal decongestants $(18.86 \%)$ and NSAID $(16.47 \%)$ of total prescription. The classes of drugs prescribed are as shown in Figure 2

\section{DISCUSSION}

Correct diagnosis of a disease $\&$ its management with medicines constitute important aspect of patient care, which is more important in case of pediatric patient. The present study is based on data obtained from 500 prescriptions. The male to female ratio reflected a higher number of male patients who are visiting clinic compared to female patients.

About 173 patients were diagnosed with upper respiratory tract infection. 81 patients were found to be diagnosed with Bronchitis. The most frequently prescribed drug class was antibiotics. About 393 patients have been prescribed with NSAIDs. Children differ from adults in their response to drugs. So, special care is needed in children and doses should always be calculated with care. $40 \%$ of patients were prescribed up to 3 drugs which was less than that in the study carried out 21 (i.e. $46.7 \%$ )

\section{REFERENCES}

1. Ghai OP. Essential Pediatrics, published by interprint A-16, Narain all, new delhi, India. $4^{\text {th }}$ edition. 1998.

2. Ghai OP, Paul VK. Rational drug therapy in pediatric practice. Indian paediatrics. 1988; 25(12): 1095-109.

3. Summers RS, summers B. drug prescribing in paediatrics. Ann trop paediatrics. 1986; 6(2): 129-33.

4. Principi N. Control of antibiotic therapy in pediatric patients. Developmental pharmacology and therapeutics. 1981; 2(3): 145-55.

5. Schollenberg E, Albritton WL. Antibiotic misuse in a pediatric teaching hospital. Can Med Assoc J. 1980; 122(1): 49-52.
\& rest $60 \%$ were prescribed 4 to 7 drugs. $^{7}$ It is comparatively more than the study done by Jason Hall 22 (i.e. $60.6 \%)^{8}{ }^{8} 3-5$ antibiotics were prescribed to $35.9 \%$ patients. Antibiotics were prescribed without investigation mainly based on clinical judgement with an average of 2.37 per prescription. At least an NSAID was prescribed to $14.28 \%$ patients. In the study only $16 \%$ of antibiotics were given by intravenous injection which was quite opposite to the study done by Thomas G23 which indicated excessive use of injectables in many developing countries. ${ }^{9}$

\section{CONCLUSION}

This study provides important insights into the prescribing patterns of drug use in the pediatrics outpatient department of a tertiary care teaching hospital. It has helped to identify irrational prescribing patterns of drugs in pediatrics. Hence, the clinical pharmacist must be considered to be an integral part of the multidisciplinary health care team. They should be involved in collection and presentation of prescribing data as part of clinical audit and also counselling of patients / care takers. Correct diagnosis of the disease and its management constitute important aspects of patient care which is even more important in case of pediatric patients.

\section{CONFLICT OF INTEREST}

The authors declare that they have no conflict of interest.

\section{ACKNOWLEDGEMENTS}

The authors duly acknowledge the contribution and help of patients and physicians of paediatric department in the tertiary care hospital without whom the study would not be possible.
6. Peter G, Micheal DR. Principles of Drug Therapy. In: Kliegman, Behrman, Jenson, Stanton, editors. Nelson Text book of Pediatrics. $18^{\text {th }}$ edn. Vol 1. Philadelphia: Saunders Elsevier; 2007. p. 331-2.

7. Mirza Nazima Y, Desai Sagun, Ganguly Barna. Prescribing pattern in Outpatient department in Gujarat; Bangladesh. Journal of Pharmacology 2009; 4(1): 112-4.

8. Jason Hall BA. Pediatric prescribing in New Zealand. NZFP. 2002; 29 12): 14-8.

9. Tomson G. Drug utilization studies in Sri Lanka-Towards an understanding of medicine in society. Thesis, Karolinska Institute, Stokholm, Sweden; 1990; I : $1-5$. 